By this / you will see that on Aprik 22nd he had got up tora fair average, hoth as regards percentage and quantity passed; and this upon a diet containing as little nitrogen as possible. On May 26th, however, you will note that the percentage had decreased to .54, and the total amount to-123: grains. This is accounted for in this way; during the five weeks' interval, I had been unable to prevail upon him to send up his urine for examination, because he did not like to trouble me ; he had lost two sisters by death, and had experienced severe family home-worries as well; at last I prevailed upon him to let me have another specimen for examination, with the result mentioned.

During all this time the Hollands was taken every night, but the appetite had been a little more indulged, especially with eggs. $\mathrm{He}$ was told to take his old mixture again, and you will see that by the end of the week, notwithstanding that the amount of urine had de. creased to 30 ounces, the percentage had increased to 1.82 , and the total urea to 16.24 grammes, or 249.1 grains.

CASE II. - Mrs. D., a visitor, aged 76 , has always enjoyed most robust health, and been a brilliant member of society. She had eaten meat in large quantities until the present time, when she usually ate it three times a day, and ate but sparingly of bread and regetables. For the last ten years, ske had drank about 20 ounces of port-wine daily. The digestive functions appeared to be in excellent order not. withstanding; and the bowels acted daily, the only aperient taken being an occasional dose of compound liquorice-powder.

The arteries were atheromatous, and brain-degeneration had been going on for some time, as evidenced by an excessively irritable temper, decided opposition to all things meant for her benefit, and dislike to old servants, etc.

She had been under numerous medical men, and, as it was thought that she might die suddenly from either apoplexy or failure of heartpower, I was asked to see her occasionally, not to treat, but to certify in case of anything untoward occurring.

She was as before described; and I found, moreover, that, as usual in such cases, she suffered very much from attacks of dyspncen, and inability to sleep, especially after the early part of the night had passed ; a great portion of the time being often spent in a chair. She was very stout, and incapable of helping herself; and, as she was incessantly wishing to get out of bed to micturate, her attendants were utterly worn out with their exertions. Very small quantities of fluid besides the wine were taken, and very little urine was passed. I believed that these dyspnœal attaoks were of an uræmic character. The pulse was 68, and the tension high. She would not take any medicine.

About a month passed, when I was sent for late one evening to see her in a more than usually severe attack of dyspnœa; which was relieved by giving one-minim doses of solution of nitro-glycerine, and one milligramme of hyoscyamine every hour. The relief was most marked, but the old lady's objection to medicine prevented her taking the dose unless the breathing was very bad; it was given, however, occasionally without her knowledge, as the port wine formed a vehicle which quite covered the taste of the medicine. She would not modify her habits. in any way, although I told her she might thereby improve both the dyspnoea and the sleeplessness.

About a fortnight later, she complained of always feeling hungry, even after eating, and, as a consequence, ate meat more largely than ever. A few days later, she vomited, but the attack passed away in a few hours, to be followed by constipation, drowsiness, and a pulse of 50. A pill containing one grain each of aloin and jalapin was given, as were also castor-oil, elaterium, etc: , but without result ; then injections; but it was not until I had injected about two quarts of gruel, with two ounces of castor-oil, through an extra long No. 12 gum eiastic catheter, that we succeded in getting an action of the bowels. All this time, the dyspnoea was severe, and the secretion of urine only 12 to 14 ounces daily. Fortunately; the appetite became bad, and we were able to keep our patient on a light milk:diet.

One minim of a 1 per cent. solution of nitro-glycerine was given every four hours, and, being tasteless, without the patient's know ledge. Very little stimulant was allowed, and was given in the form of Hollands and spruce-beer.

The condition was procarions for some days but a gradual and marked improvement took place; the 'bowels acted freely, with the occasional help of a dose of 'castor-oil ; the quantity and quality of the urine steadily improving, as follows :

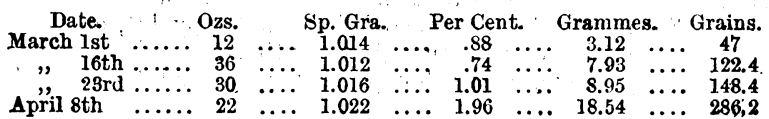

1. On April 15th, the old lady was so much better, that, I was ablo to taket her back to town, and hand her over to the care of her ' own medical man.

In my practice, I have a large percentage of gout-oases, and find that in all there appears to be a deficient excretion of urea, increasing with the age of the patient. This may be, and probably is, to a corri tain extent, a result of the patients being kept as much as they will allow upon a non-nitrogenous diet; it may also show that granulap mischief is advancing in the kidney, and, again, that a certain portion of the urea has been converted into uric acie, and stored up in the system.

As an instance of the latter, I would mention the following exa mination of urine in a patient aged 50, who was suffering from a typical attack of gout in the feet.

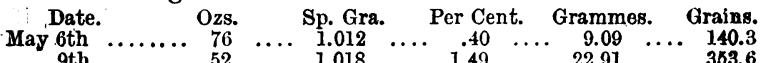

This change for the better took place in three days, under the influence of saline aperients and colchicum, with a corresponding improvement in the symptoms and feelings of the patient.

In all cases where a deficient excretion of urea takes place, it is important to remember that there may be a deficient power of filtering this product of waste tissue and of nitrogenous food from the blood, and that it is therefore a necessity to withhold as much as possible the ingestion of azotised matter, and also to limit the amount of exercise taken.

Saline aperients are valuable, as it has been proved by actual experiment that urea is eliminated much more freely under their inHluence; besides which, they do not depress patients who take them regularly.

Next it is important that the skin should be kept freely acting; and for this purpose it is well to take a hot sponge-bath every morning, using a little soap, and a rough towel afterwards. The body should not be exposed to chill, and should be warmly clad, not too warmly so as to weaken the skin, but sufficiently so to protect it from the sudden changes of our climate. Stimulants should be avoided, or if taken, should be freely diluted with water. As a rule, I find that Hollands and spruce-beer are the best; both are good diuretics, especially the latter.

At the present time, I see that nitrite of amyl is being extolled as a good eliminator of uric acid. For four years or more I have known that nitroglycerine was the most efficient means we have of increasing the excretion of urea, and have published cases of uræmic and puerperal eclampsia relieved and cured by its use. In all probability, it acts in the same manner as nitrite of amyl, by dilating the blood-vessels, and so relieving the circulation through the kidney. At all events, I look upon it as the best diuretic we possess in such cases; and all the more so, that it seems to have the power of acting freely upon the bowels at the same time.

Defective action of the kidneys can be compensated by rousing the skin and bowels into compensatory activity; consequently, when the bowels become constipated in renal inadequacy, they should be promptly acted upon. At the same time, it is well to stimulate the sudoriferous glands of the skin.

When a fall in the excretion of urea is disturbing the system, it is well, first, to cut down the albuminoid elements of food; secondly, to increase renal excretion; thirdly, to act upon the bowels and skin. But the only way to ascertain this fall in the excretion of urea, is to test the urine in the manner described daily, or, at any rate, frequently, in all suspicious cases.

\section{ON SEPTICAMIA.}

Read before the South-East Hants District of the Southern Branch. BY JOHN ROBERT KEALY, M.D., A.K.C.,

Physician to Out-Patients at the Royal Portsmouth, Portsea, and Gosport Hospital.

Some of us here are old enough in the profession of medicine and surgery to know that in our student days the title or designation of my paper-septicæmia-was an unknown term. Search authors of the period to which I refer, even dictionaries of medicine and surgery, and the term will not be found. Pyohæmia or pyæmia you may find, but not septicæmia. It became a matter of question as to tho possible absorption of the pus-cell into the blood-system; and, subsequently morbid conditions were recognised by which a new pathology nade the distinetions of septicæmia and pyæmia different, and not eonvertible, terms. Hence, we now understand septicæmia (the, subject of my; paper) to be a constitutional, generally acute, disease, due to 
the absorption of various putrid substances into the blood, by which the blood is spoiled, so that it cannot fulfil its physiological functions. Certain circumstances are necessary for putrid matter to be taken into the blood of man ; such substances are only taken through the healthy skin and mucous membranes when the putrid substances have a destructive or cauterant action, or an active power of pene trating, like fungi or infusoria. Diseased skin or wound-surfaces take up such putrid matters more readily, but even they only do so under certain circumstances ; for instance, they do not readily pass through well organised uninjured granulations ; the poison is absorbed chiefly by the lymphatic vessels. What is the principal, or even subsidiary, part played in the pathogeny of septicæmia, is as yet undetermined.

Leaving much that might be discussed and illustrated here, we pass on to ask, What characterises the course of septicæmia? We note, as to the nerve-symptoms, the patients are apathetic and sleepy, if not entirely comatose ; rarely there is fearful excitement, and occasion. ally maniacal delirium; at the same time, the subjective feelings are good ; the patients usually do not suffer much. The tongue is dry, often as hard as wood, which renders the speech very peculiar; the patients are thirsty, rarely drink, on account of their great apathy. Not always, but very frequently, there is profuse diarrhoea ; more rarely, vomiting. At first, there may be great sweating; later, the skin is dry and flabby. The urine is scanty, very concentrated, and occasionally albuminous. As the disease progresses, the patient passes her urine and fæces in bed. Bed-sores over the sacrum occur early. The temperature rises high; initial chills are very rare ; intercurrent chills may or may not occur.

In the prognosis of septicæmia, the condition of the pulse and tongue are more important than the temperature. A small, frequent pulse and dry tongue are bad signs, while a normal temperature has no prognostic value; very high or very low temperature makes the prognosis worse. Cases occur where the onset of the fever is scarcely marked by an elevation of temperature; and, lastly, some cases run their course without fever, or with abnormally low temperature-for example, old persons with spontaneous gangrene. From what I have stated, and from what I shall show you presently in my case, falling of temperature is of itself by no means a sign of improvement; but the other constitutional symptoms (strength, mental state, pulse; tongue, etc.) must also be taken into consideration. Where the symptoms of the disease are marked, as they were in my case, the prognosis is very bad.

CASE. -Mrs. X., aged 28, tall and slender in form, of bright and hopeful disposition, had had three living children and three miscarriages.

During September, 1884, she considered herself weak from a four months' conception. From the middle of the month, she had a slight reddish discharge per vaginam, and sensation of cold and weight about the hypogastrium. I gave her five grains of gallic acid three times a day.

October 8th, at 9.30 P. M. I was summoned hurriedly to visit her. I found her in bed, on her back, with a pot de chambre between her thighs. In it was a somewhat putrid embryo, about the fourth month, with a shrivelled funis still connected. I divided the funis removed the utensil, placed the patient on her left side, and examined for the placenta, which I found at the entrance of the os uteri. The cervix and body of the uterus, as far as felt, were peculiarly soft, as though made up of softened brown paper; I therefore determined not to handle the parts, but leave the placenta to be thrown off vis a tergo, rather than by a vis a fronte. The placenta was expelled about seventeen hours after the embryo; and, on my second visit, the patient was cheerful, and everything appeared externally well ; but her legs were subjectively very cold. Twenty-four hours afterwards, at my visit, she complained of acute pain over the lower half of the right lung. The percussion-note was low, and there were mucous rales. Feeling very ill in the night, when on the commode, she became somewhat insensible, and foll off. The next morbid condition developed was a swollen right shoulder-joint, without any sign of a bruise. At this point of the case, I came to the conclusion that I had to deal with a case of septicæmia. Although no particular smell was observed from the vagina, I ordered injections of carbolic lotion ( 1 in 40). No tenderness was observed about the pelvis, however hard the pressure.

The temperature on the ninth day of attendance had risen to $102^{\circ}$; pulse 108 ; respirations 30 .

On the next day, the whole of the fauces, with the entire mucous membrane of the mouth and tongue, were covered with diphtheritic membrane.

On the thirteenth day, the patient was greatly depressed, and profuse diarrhoes set in, with a temperature of $103^{\circ}$. The day after this, she had a severe attack of rigors, during which she seemed as though she would die. These rigors continued twice in the twenty-four hours for some time, and then, at irregular intervals, for more than a month. The diarrhoea continued up to the end of the first week in November. The stools were of a most offensive character until November 4th, when a quantity of curry-like motion came away, and, two dajs afterwards, a green evacuation; from that time, the motions improved.

In a few days after the swelling of the right shoulder had subsided, the left became swollen, and eventually subsided under the application of iodine, as did the other.

On November 1st, twenty-fourth day of illness, the pulse and temperature suddenly fell ; the conjunctivæ were yellow-tinged; the coccyx and sacrum quickly became the seat of bed-sore.

The next day, November 2nd, she had profuse vomiting, and was excessively prostrated. This day appeared to me a crisis; the same condition came on the two following Sundays, only not so severe. Both lungs, from apices to bases, were now involved with râles; she had an incessant cough, with expectoration of an albuminoid character. Improvement not having come as wished, I resolved upon using a grain of iodoform, mixed up with extract of gentian, to be taken every four hours. After twelve doses the effects were marked, the rales ceasing, the cough abating, and the expectoration lessening. She was well fed on tripe boiled in milk.

On November 20th, she had rigors again, anorexia for two days, with most acute pain in the left sacro-iliac joint, succeeding the subsidence of the swelling in the left shoulder. The slightest movement caused agony. No pain was produced by firm pressure over the inguinal region or up to the umbilicus on the same side. The bed-sore improved fast, and ultimately healed. I gave her full diet, and cod-liver oil with hypophosphites. She gained flesh well, and in January, 1885 , began to go out; then menstruation occurred in regular order afterwards.

The above case was one of immense trouble and anxiety. The diagnosis turned out from the first correct. At the early stage of the condition, I surmised the possibility of a second putrid embryo, but such proved not to be the case. Then one was much importuned by the friends to stop the diarrhœa ; but being a firm believer in nature's work of eliminating disease, I refused. What meant the rigors, so oft and irregularly repeated? What the apparently critical stages on three consecutive Sundays ? The temperature ranged between $104.6^{\circ}$ and $99^{\circ}$; for the greater part of the illness, $102^{\circ}$. The maximum of pulse was 120 ; and of respiration 36.

\section{PARTIAL DISLOCATION OF THE HEAD OF THE RADIUS PECULIAR TO CHILDREN.}

BY SIDNEY H. LINDEMAN, M.R.C.S., House-Surgeon to the West Norfolk and Lynn Hospital.

No department of medicine or surgery meets with more lay criticism and quackish opposition, than that which has for its aim the setting of bones and the reduction of dislocations. The reason is, I think, easily seen. Medical education was once far different from what it is now. The medical student's career of Bob Sawyer's time consisted in walking round the wards of a hospital, occasionally attending the classes of a popular lecturer, and, finally, just scraping through an examination. It was then that the unqualified bone-setter arose and flourished. The bone-setters of the present day have changed in many ways, but there is no need to describe them or their modus operandi. Suffice it to say, that they have become more cautious, and have even, in some instances, been indiscreet enough to take a qualification, forgetting that, by so doing, they lose their standpoint. There is no doubt, however, that they should be things of the past, and they will gradually sink into oblivion. These remarks, which are perhaps rather irrelevant to the subject of this paper, have been made because similar injuries to the one about to be described frequently fall into the hands of the bone-setters, and help to form the rock on which their reputation stands. For, by rapidly and forcibly putting joints through all their movements, they often blindly do the very thing required. No medical man should be, or is generally, forgiven by the public for making errors in the diagnosis of dislocations and the treatment of fractures, which an unqualified man may afterwards rectify. Such errors are the cause of immense mischief, not only to the particular medical attendant, but to the whole of the profession. For it must be remembered that one happy hit, on the part of the bone-setter, is quite enough to ontbalance a dozen mistakes which he may make, even though they may lead to incalculable mischief. 